\title{
Resistant Starch a New Weapon against Disease Fighting of Potato Eater: A focused review
}

\author{
Rajesh Chakraborty', Tuhin Suvra Roy ${ }^{1}$, Md. Quamruzzaman', \\ Marjana Yeasmin ${ }^{1}$, Niranjan Bandopaddhya ${ }^{2}$
}

${ }^{1}$ Departmant of Agronomy, Sher-e-Bangla Agricultural University, Dhaka 1207, Bangladesh, ${ }^{2}$ Department of Soil Science, Sher-e-Bangla Agricultural University, Dhaka 1207, Bangladesh

\begin{abstract}
Conventionally, the potato eater of Bangladesh intakes the normal starch from their potato foodstuffs. However, the phenomenon, "resistant starch (RS)" is the most crucial for our health and body against diseases. From these perspectives, this study was conducted to evaluate the most precise characteristics of RS from which we can get more and more benefits to lead a better life from potato. The interest of RS of potato varied from men to men and the intensity of taking the RS depends on the amount of starch intake. It can regulate the insulin and blood sugar. The cooking procedures and the cooling techniques may vary the amount of starch of potato which is indigestible in nature. After cooking, the cooling increases the percent of RS of potato. Finally, it may be said that the RS could change our health into a good sign as healthy men.
\end{abstract}

Key words: Blood sugar, cooling after boiling, insulin, normal starch, resistant starch

\section{INTRODUCTION}

What is resistant starch (RS)

$\mathrm{W}$ Then you think about "starch," what comes to mind? Glucose, carbs, elevated blood sugar, insulin spikes, glycogen repletion, etc., basically, we think about starch that we (meaning our host cells) can digest, absorb, and metabolize as glucose (for better or worse). Officially, RS is "the sum of starch and products of starch degradation not absorbed in the small intestine of healthy individuals." Instead of being cleaved in twain by our enzymes and absorbed as glucose, RS travels unscathed through the small intestine into the colon, where colonic gut flora metabolize it into short chain fatty acids. Thus, it is resistant to digestion by the host. ${ }^{[1]}$

\section{Typology of RS}

Not all RSs are the same. There are four different types: ${ }^{[2]}$

- Type 1 is found in grains, seeds and legumes and resists digestion because it is bound within the fibrous cell walls

- Type 2 is found in some starchy foods including raw potatoes and green (unripe) bananas
- Type 3 is formed when certain starchy foods, including potatoes and rice, are cooked and then cooled. The cooling turns some of the digestible starches into RSs via a process called retrogradation ${ }^{[3]}$

- Type 4 is man-made and formed via a chemical process.

From the above classification, it may be mentioned that potato and potato starchy products in belonging to Types 2 and 3 .

\section{DISCUSSION}

\section{The working fantasies of RS}

Most of the carbohydrates in the diet are starches. Starches are long chains of glucose that are found in grains, potatoes, and various foods. But not all of the starch, we eat gets

\author{
Address for correspondence: \\ Rajesh Chakraborty, Department of Agronomy, \\ Sher-e-Bangla Agricultural University, Dhaka 1207, \\ Bangladesh. Tel.: +88-01741664970, \\ Fax: +88-0258155800. \\ E-mail: rajeshmadhobi9@gmail.com
}

Received: 15-05-2016

Revised: 26-06-2016

Accepted: 15-07-2016 
digested due it does not break down to glucose. Sometimes a small part of it passes through the digestive tract unchanged. In other words, it is resistant to digestion. This type of starch is called RS, which functions kind of like soluble fiber. ${ }^{[4,5]}$

Eventually, it reaching the colon where it feeds the friendly bacteria in the gut. ${ }^{[5]}$ The gut bacteria digest the RS into shortchain fatty acids, which are absorbed by the body. Therefore, RS will not act as a carbohydrate. Instead, it is food for gut bacteria and what your body absorbs has been converted to fat. RS is in reality low carb, high fat - with food for the gut flora as a bonus. Feeding the good gut bacteria - and the cells of the intestinal lining - seems to be able to affect hormone levels in the body (glucagon-like peptide 1, etc.), which in turn has an effect on blood sugar regulation and insulin sensitivity. It seems also to be beneficial to ensure that gut bacteria and cells get adequate nutrition. Our ancestors no doubt did so as there are plenty of sources of RS in nature [Figure 1]. ${ }^{[6]}$

The bacteria in the intestine (the gut flora) outnumber the body's cells 10 to 1 . In that respect, we are only $10 \%$ human. ${ }^{[8]}$ Whereas most foods we eat feed only $10 \%$ of our cells, fermentable fibers, and RSs feed the other $90 \%{ }^{[9,10]} \mathrm{RS}$ feeds the friendly bacteria in the intestine having a positive effect on the type of bacteria as well as the number of them. ${ }^{[11]}$

When the bacteria digest RSs, they form several compounds, including gasses and short-chain fatty acids, most notably a fatty acid called butyrate, ${ }^{[12,13]}$ this are finally absorbed by the body.

\section{Benefits against health and disease fighting}

For over three decades, studies have looked at the health benefits of RS in humans, and the results are pretty amazing. RS has been shown to enhances insulin sensitivity, ${ }^{[14]}$ lowers blood sugar levels, ${ }^{[15-17]}$ improves metabolic health and various benefits for digestion. ${ }^{[18]}$ Increase absorption of important minerals like calcium and magnesium. Decrease absorption of toxic and carcinogenic compounds. Affect positive changes in microflora, particularly increasing bifidobacterium. It also has a "second meal effect" - meaning that if you eat RS with breakfast, it will also lower the blood sugar spike at lunch. ${ }^{[19]}$ The effect on glucose and insulin metabolism is very impressive. Some studies have found a 33-50\% improvement in insulin sensitivity after 4 weeks of consuming $15-30 \mathrm{~g} /$ day. ${ }^{[20]}$ The importance of insulin sensitivity cannot be stressed enough. Having low insulin sensitivity (insulin resistance) is believed to be a major causal factor in some of the world's most serious diseases including metabolic syndrome, Type 2 diabetes, obesity, cardiovascular disease, and Alzheimer's disease. By improving insulin sensitivity and lowering blood sugar, RS may help you avoid chronic disease and may make you live both longer and better [Figure 2].

Increase feelings of satiety:[22] $\mathrm{RS}$ has fewer calories than regular starch ( 2 vs. 4 calories/g). Hence, the more RSs found in food, the fewer calories it will contain. Several studies

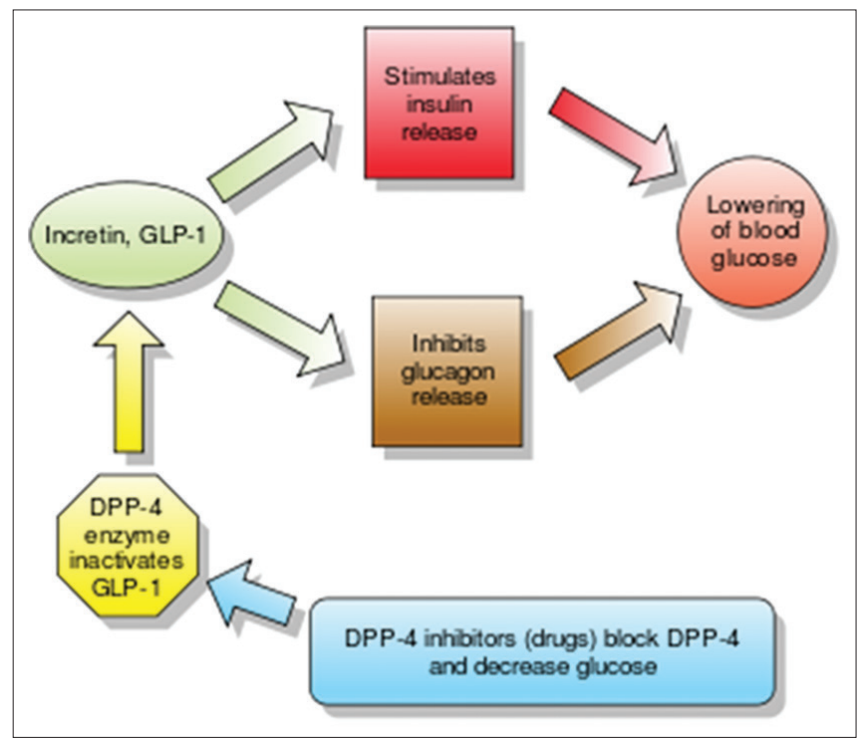

Figure 1: Regulation of insulin and blood sugar by the action of resistant starch ${ }^{[7]}$

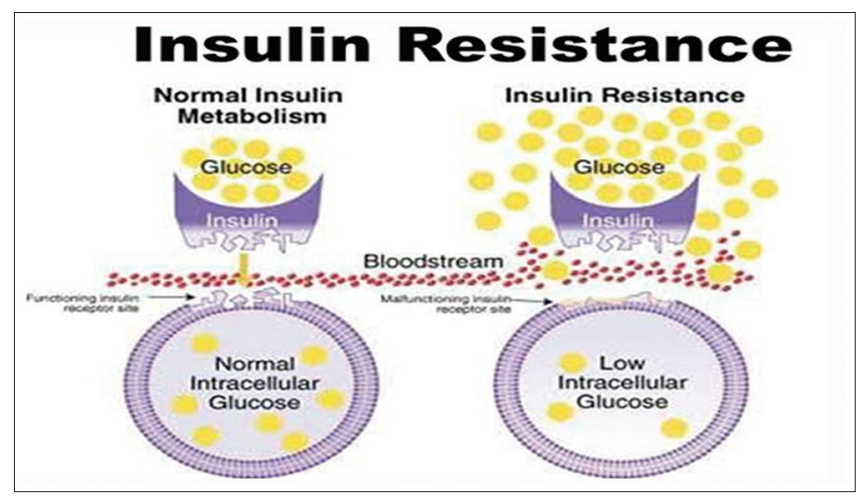

Figure 2: Fate of normal and resistant insulin through our bloodstream Source ${ }^{[21]}$

show that soluble fiber supplements can contribute to weight loss, primarily by increasing feelings of fullness and reducing appetite. ${ }^{[23]}$ It looks like RS has the same effect. Adding RS to meals increases feelings of fullness and makes people eat fewer calories. ${ }^{[2]}$ There are some studies in animals showing that RS can cause weight loss, but this has not been studied properly in humans yet. I personally doubt that adding RS to your diet would lead to any major effect on your weight, but it might make it easier to lose weight with other methods. It reduces the $\mathrm{pH}$ level, potently reduces inflammation and leads to several beneficial changes that should lower the risk of colorectal cancer, which is the fourth most common cause of cancer death worldwide. ${ }^{[25,26]}$ Because of its therapeutic effects on the colon, RS may be useful for various digestive disorders. This includes inflammatory bowel diseases such as ulcerative colitis and Crohn's disease, constipation, diverticulitis, and diarrhea. ${ }^{[2]}$

\section{Why we should add RSs to our diet?}

Prebiotics are indigestible carbohydrates, or at least indigestible to us that reaches the colon intact and selectively feed many 
strains of beneficial bacteria. Prebiotics are generally classified into three different types: Non-starch polysaccharides (such as inulin and fructooligosaccharide), soluble fiber (including psyllium husk and acacia fibers) and RS. Each of these types of prebiotics feeds different species of gut bacteria, but among these, RS is emerging as uniquely beneficial. ${ }^{[28]}$

\section{How to add RSs to our diet?}

There are two ways to add RSs to our diet either get them from foods, or supplement with them. Several commonly consumed foods are high in RS. This includes raw potatoes, cooked and then cooled potatoes. As we can see, these are all high-carb foods, so they are out of the question if you are currently on a very low-carb diet (although you can fit some in if you're on a low-carb diet with carbs in the 50-150 g range which is also low-carb). That being said, we can add RS to our diet without adding any digestible carbohydrates. For this purpose, many people have recommended (and are getting good results with) Bob's red mill raw potato starch.

Raw potato starch contains about $8 \mathrm{~g}$ of RS per tablespoon and almost no usable carbohydrate. It's very cheap too. It tastes kind of bland and you can add it to our diet in various ways, by sprinkling it on our food, mixing it in water, putting it in smoothies, etc. Four tablespoons of raw potato starch should provide $32 \mathrm{~g}$ of RS. It is important to start slowly and work your way up, because too much, too soon can cause flatulence and discomfort. There's no point in taking much more than that, because when you reach 50-60 g/day, the excess seems to just pass through. It may take time (2-4 weeks) for the production of short-chain fatty acids to increase and to notice all the benefits, so be patient. ${ }^{[29]}$

\section{Preparing methods}

We get RS from the food we eat. The highest sources are raw potatoes, cooked, and cooled potatoes. But still now, there is no specific target for RS intake. However, preliminary data shows that the average American woman consumes about $4 \mathrm{~g}$ of RS each day. Experts such as Gerbstadt believe the research is strong enough to advocate doubling that. Adding just $1 / 2$ to 1 cup of cooled RS-rich food per day can do the trick.

Keep it cool in cooked starchy foods, RS is created during cooling. Cooking triggers starch to absorb water and swell, and as it slowly cools, portions of the starch become crystallized into the form that resists digestion. Cooling either at room temperature or in the refrigerator will raise RS levels. Just do not reheat. That breaks up the crystals, causing RS levels to plummet. ${ }^{[30]}$

\section{Drawbacks of RS}

The people with gut dysbiosis, especially small intestinal bacterial overgrowth (SIBO) may be affected by RS from potato. In SIBO, bacteria that ought to be in the large intestine spill over into the small intestine as well. These are the bacteria that just love a nice dose of RS - if you give them that food, they'll grow and multiply just like they would in the large intestine. But that's exactly the opposite of what you want to happen! Think about it: If you already have a gut flora overgrowth, the absolute last thing you want to do is give your gut flora an all-you-can-eat buffet. That does not make RS bad; it just means it's not for everyone, and a quick look at the waters is very wise before you jump in with both feet. ${ }^{[31]}$

\section{CONCLUSION}

Finally, we can say that, if the potato eaters of Bangladesh starts to take the RS from their diverse potato stuffs so that they will be highly benefited against chronic diseases, specially, increased blood sugar problems, diabetics, cancer, respectively. However, they should be curious for the quality of food intake, which must be enough in much amount of pure RS and should be purchased from liable sources.

\section{Future projections and industrial prospects}

The potato research body of Bangladesh should start to conduct the research on screening the variety those content the more RS properties, i.e. the varieties convert their normal starch granules into resistant or indigestible in our guts after ingest in a very short time. People responses on RS should also be counted through a regional survey. The potato industrialist of Bangladesh can start to produce the potato products (chips, flakes, flours, French fries, etc.) by using the variety those are more resistant in nature.

The modern potato user in Bangladesh could purchase the potato flour which contents the more resistant granules. As results, the owner of potato industry will get more money instead of conventional wheat/wheat-maize flour marketing. Ultimately, the potato exporters could get more foreign currencies by exporting the better screened potato varieties and quality products.

\section{REFERENCES}

1. Available from: http://www.marksdailyapple.com/thedefinitive-guide-to-resistant-starch/\#axzz2z7gPql1 m. [Last accessed on 2016 Jan 23].

2. Sajilata MG, Singhal RS, Kulkarni PR. Resistant starch-A review. Compr Rev Food Sci Food Saf 2006;5:1-17.

3. Haralampu SG. Resistant starch-A review of the physical properties and biological impact of RS 3 . Carbohydr Polym 2000;41:285-92.

4. Available from: http://www.authoritynutrition.com/ resistant-starch-101. [Last accessed on 2016 Jan 13]. 
5. Englyst HN, Kingman SM, Hudson GJ, Cummings JH. Measurement of resistant starch in vitro and in vivo. $\mathrm{Br} \mathrm{J}$ Nutr 1996;75:749-55.

6. Available from: http://www.dietdoctor.com/potatostarch-lchf-resistant-starch. [Last accessed on 2016 Feb 20].

7. Available from: http://www.en.wikipedia.org. [Last accessed on 2016 Feb 23].

8. Sears CL. A dynamic partnership:Celebrating our gut flora. Anaerobe 2005;11:247-51.

9. Macfarlane S, Macfarlane GT, Cummings JH. Review article: Prebiotics in the gastrointestinal tract. Aliment Pharmacol Ther 2006;24:701-14.

10. Brown I, Warhurst M, Arcot J, Playne M, Illman RJ, Topping DL. Fecal numbers of bifidobacteria are higher in pigs fed Bifidobacterium longum with a high amylose cornstarch than with a low amylose cornstarch. J Nutr 1997;127:1822-7.

11. Wang X, Brown IL, Evans AJ, Conway PL. The protective effects of high amylose maize (amylomaize) starch granules on the survival of Bifidobacterium spp. In the mouse intestinal tract. J Appl Microbiol 1999;87:631-9.

12. Topping DL, Clifton PM. Short-chain fatty acids and human colonic function: Roles of resistant starch and nonstarch polysaccharides. Physiol Rev 2001;81:1031-64.

13. Wong JM, de Souza R, Kendall CW, Emam A, Jenkins DJ. Colonic health: Fermentation and short chain fatty acids. J Clin Gastroenterol 2006;40:235-43.

14. Johnston KL, Thomas EL, Bell JD, Frost GS, Robertson MD. Resistant starch improves insulin sensitivity in metabolic syndrome. Diabet Med 2010;27:391-7.

15. Behall KM, Hallfrisch J. Plasma glucose and insulin reduction after consumption of breads varying in amylose content. Eur J Clin Nutr 2002;56:913-20.

16. Alexander D. Postprandial effects of resistant starch corn porridges on blood glucose and satiety responses in non-overweight and overweight adults. Graduate Thesis and Dissertations; 2012.

17. Raben A, Tagliabue A, Christensen NJ, Madsen J, Holst JJ, Astrup A. Resistant starch: The effect on postprandial glycemia, hormonal response, and satiety. Am J Clin Nutr 1994;60:544-51.

18. Nugent AP. Health properties of resistant starch. Nutr Bull 2005;30:27-54.

19. Brighenti F, Benini L, Del Rio D, Casiraghi C,
Pellegrini N, Scazzina F, et al. Colonic fermentation of indigestible carbohydrates contributes to the secondmeal effect. Am J Clin Nutr 2006;83:817-22.

20. Maki KC, Pelkman CL, Finocchiaro ET, Kelley KM, Lawless AL, Schild AL, et al. Resistant starch from high-amylose maize increases insulin sensitivity in overweight and obese men. J Nutr 2012;142:717-23.

21. Richard C, Susan B. Resistant starch. The Cooking Cardiologist. 2015. p. 10. Available from: http:// www.southdenver.com/wp-content/uploads/2012/09/ Resistant-Starch-for-web.pdf. [Last accessed on 2016 Jan 17].

22. Available from: http://www.wellnessmama.com/17005/ resistant-starch-gut-superfood. [Last accessed on 2016 Jan 23].

23. Ramos SC, Fonseca FA, Kasmas SH, Moreira FT, Helfenstein T, Borges NC, et al. The role of soluble fiber intake in patients under highly effective lipid-lowering therapy. Nutr J 2011;10:80.

24. Willis HJ, Eldridge AL, Beiseigel J, Thomas W, Slavin JL. Greater satiety response with resistant starch and corn bran in human subjects. Nutr Res 2009;29:100-5.

25. Hylla S, Gostner A, Dusel G, Anger H, Bartram HP, Christl SU, et al. Effects of resistant starch on the colon in healthy volunteers: Possible implications for cancer prevention. Am J Clin Nutr 1998;67:136-42.

26. Zimmerman MA, Singh N, Martin PM, Thangaraju M, Ganapathy V, Waller JL, et al. Butyrate suppresses colonic inflammation through HDAC1-dependent Fas upregulation and Fas-mediated apoptosis of T cells. Am J Physiol Gastrointest Liver Physiol 2012;302:G1405-15.

27. Bird AR, Brown IL, Topping DL. Starches, resistant starches, the gut microflora and human health. Curr Issues in Intest Microbiol 2000;1:25-37.

28. Chris K. How resistant starch will help to make you healthier and thinner. Available from: http://chriskresser. com/how-resistant-starch-will-help-to-make-youhealthier-and-thinner/. [Last accessed on 2016 Feb 25].

29. Available from: http://www.authoritynutrition.com/ resistant-starch-101. [Last accessed on $2016 \mathrm{Feb} 23$ ].

30. Available from: http://www.prevention.com/food/ healthy-eating-tips/resistant-starch-natural-fat-burner. [Last accessed on 2016 Jan 23].

31. Available from: http://www.paleoleap.com/resistantstarch/. [Last accessed on 2016 Jun 26].

Source of Support: Nil. Conflict of Interest: None declared. 